Session 2660

\title{
Globalization of Engineering Curricula in the United States and Abroad
}

\author{
Morteza Sadat-Hossieny, Seyed M. Allameh, Mark Rajai \\ Northern Kentucky University
}

\begin{abstract}
With globalization of corporations and multinational industrial complexes, engineering students need the expertise necessary to face the challenges presented to them as the result of globalization. Engineering curricula are affected as the result of globalization. Modern engineering needs to address new concepts in team management, communication skills, and problem solving. Outsourcing practices and NAFTA initiatives have further intensified the globalization of science and industry to unanticipated levels. A study will be conducted to examine innovative methods and practices undertaken by engineering schools across the United States and to create curricular paradigms such as the Global Engineering College (GEC) or virtual engineering college. The findings of this study will include the challenges these institutions face exploring and implementing the innovative concepts that they have undertaken.
\end{abstract}

\section{Introduction}

Higher education institutions across North America and Europe have started a number of initiatives to increase the overall effectiveness of engineering education and to prepare students for today's global economy. These initiatives vary in scope and range from a single course in an engineering program to a global engineering college or global engineering alliances. The cultural and economic effects of globalization have created fundamental changes that are driving a new structure for engineering education. Examples of these changes are the R\&D work in Finland aimed at developing and implementing a new structure for Engineering Education (EE). New curricula directed toward globalization are also being implemented by German universities. Introduction of these globalization initiatives is a clear affirmation that European countries have realized the urgency for global engineering curricula. That might be explained partly due to the unification of Europe and the issue of rapidly growing globalization.

Although internationalization may have started from the social sciences and humanities, engineering and the natural sciences in the United States have realized that engineering students also require strong international skills to succeed in the global engineering workforce. As early as April 1995, PRISM, the journal of the American Society of Engineering Education (ASEE), mentioned over 70 engineering programs with some components related to internationalization and globalization. During the years, with the realization of the importance of such programs, the number of engineering programs has grown larger, and collaborative development teams have rapidly evolved into

"Proceedings of the 2005 American Society for Engineering Education Annual Conference \& Exposition Copyright (C) 2005, American Society for Engineering Education"” 
international collaborative teams. ${ }^{1}$ Students graduating from an engineering program can expect to work at some point in their career, on teams with individuals from different cultural and linguistic backgrounds from various locations in different continents.

Doerry $^{1}$ explains that international programs for engineering students have had limited impact on engineering education as a whole. These programs have remained curiously peripheral; students participating in these programs remain relatively small. To understand the reason why so few students choose to gain "international experience" as part of their engineering education, a survey of the College of Engineering and Technology (CET) graduates was conducted. The survey revealed obstacles like challenging curriculum, language barriers, semester timing, perceptions and marketing of the programs. He further concludes that "Remedying this condition clearly calls for a comprehensive curricular reform that will make international engineering education attractive to all undergraduates."

This paper provides excerpts of the major initiatives taken to transform engineering curricula in Finland, Germany, and Great Britain. A valuable snapshot of the status of Engineering Education (EE) in the United State as a major player in the globalization of Engineering Education is also provided. Finally, efforts underway to globalize engineering education at Northern Kentucky University and other regional universities at Midwest region of United States are discussed.

\section{Effective Teaching Practices for Globalization of Engineering Education}

The primary issue underlying any kind of internationalized engineering education is the adoption of the correct standard teaching practices. Some fundamental issues in teaching engineering subjects include: curriculum design and evaluation, liberal education for engineers, use of new technologies in engineering education, international collaborations, education for sustainable development, exchange mechanisms in engineering education, academic/industry collaborations, international mobility, linkages between developed and developing countries, and effective management of academic and engineering institutions. $^{2}$

Critical thinking and problem solving are important skills that need to be developed for students in an undergraduate program. Critical thinking is one of the several ABET program outcomes that are difficult to achieve using traditional approaches to engineering education. For example, engineering graduates need to have the broad education necessary to understand the impact of civil engineering solutions in a global and societal context. There is much to be gained from broader application of the philosophies and techniques to the education of engineers. ${ }^{3}$ Problem solving in specific cannot be simply a series of stand-alone assignments or projects. It must thus be coordinated between the faculty members, students, and perhaps industry involved in order to provide a meaningful experience for students. ${ }^{2}$

The need for laboratory development is an important component of engineering education and is viewed as an ongoing innovation in teaching and learning 
methodologies. Variety and balance in teaching methods and appropriate technologies should be utilized in the delivery of the subject matter being taught.

\section{Transforming Engineering Education using the system approach}

This initiative describes the ongoing R\&D work unique to Finland at this time, to make a fundamental transition from the routine operating mode to a systematic development mode in EE (the same model used in the cooperate world).

Developing and implementing a new EE model that meets the requirements of the complex global environment is the main goal for the system approach. The complexity of the development of the new EE model requires a systematic approach. The work has been done as an engineering endeavor with a combination of theoretical and experimental work, utilizing a new approach based on systems and model thinking.

Realizing the new demands on the EE institutions for deeper learning, more efficient and innovative teaching, the responsibility for student employment, and the responsibility to society, the transition to the development mode is still at its infancy. ${ }^{4}$ The profound changes in societies and recent technological developments have had relatively little effect on the curricular structure of the EE. Most of the current EE organizations and programs have been implemented in slowly changing organizations. The current EE model is based on the education structure and the curriculum implemented in the U.S. in the late 1940s. The emphasis of the present EE must be on quantity, aiming to include everything an EE student needs during his/her career. "This way of doing things has led to overloading, incoherence and the lack of the ability to combine knowledge into functioning wholes in the real world ${ }^{5} . " 4$

The discrepancies between the higher education institutions and their industrial customers can no longer be solved partially within the present operating mode: e.g. adding subjects/courses/projects/work practice, adopting new teaching methods, and exploiting new technology. Only by changing the present EE to a new structure and rapid advances in Information and Communications Technology offer great possibilities to remedy the problems.

Systems engineering approach is described as the classical scientific approach that divides the surrounding world into a large number of separate scientific disciplines and sub-disciplines. With the systems engineering approach, complex real-world systems are usually described as hierarchical (multilevel) systems. The systems are separated into subsystems. Accordingly, the structure and operation of the systems can be separated to the operational level (how), tactical level (who, what, where, when), and strategic level (why) connected with the goals of the system. It tries to manage the extreme complexity of the world by treating the world as a collection of functional entities (dynamical systems) consisting of material, energy, and information and by describing these systems with the best models available. ${ }^{4}$

As part of this model, a sequence of real-world projects is used as a means for creating an effective learning environment - "learning by doing and experiencing". The basic 
knowledge for the learning projects is provided to students by faculty in the form of compact lectures called "information flashes". Modern information and communications technology plays a central role in the development of the new EE system. It is used as a basic means of delivering instructional materials to students on scheduled bases.

The deficiencies of the present EE is believed to be the underlying notion that the model for the human being is a physical (nonliving) object. The goal of the present EE model is to fill all students, regarded e.g. as a vessel, a partially filled cup or a machine or computer, with a similar knowledge to last their whole lifetime. Educators are understood mainly as dispensers for filling the cups. This model is based on the definition of the competence requirements for the engineering graduates working in the global environment. The goal is on learning the engineer's systematic and creative way of thinking and doing real-world tasks. ${ }^{4}$

\section{Modernization/Globalization of Engineering Education in German and British Universities}

Based on the article published by Detert ${ }^{5}$, politicians and educators are demanding that the German education system adopt the Anglo-American system in an attempt to modernize engineering education in German universities. This is believed to open the system up to globalization and introduce new curricula geared toward attracting more international students to study in German universities.

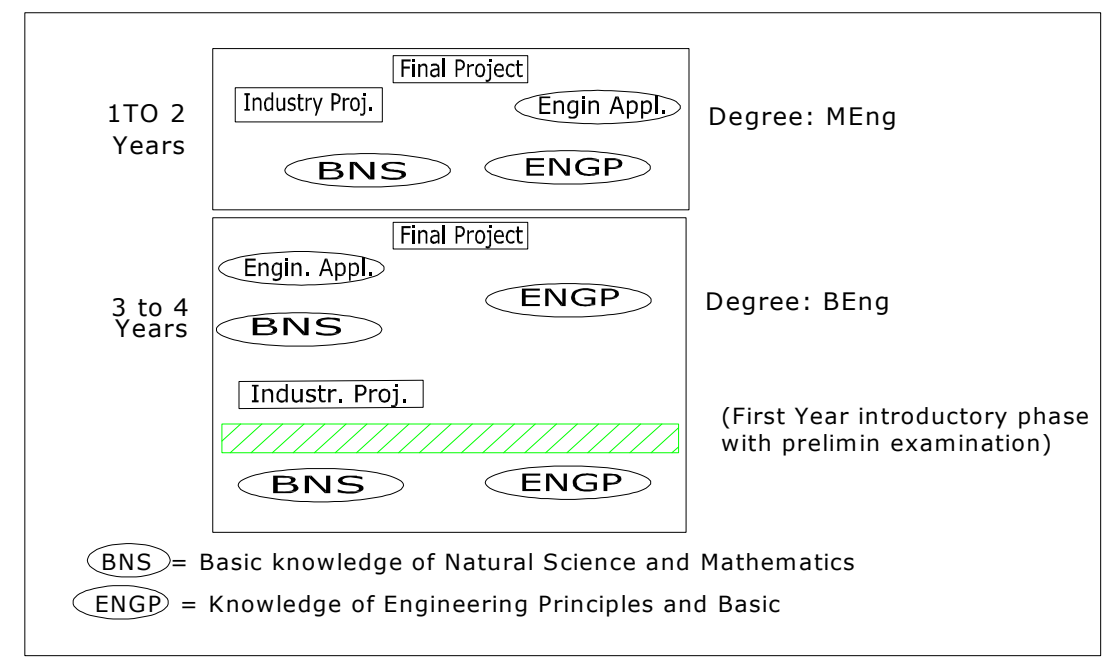

Figure 1: Structure of the new curricula in Germany with bachelor and master's degrees, adopted from Global J. of Engng. Educ., Vol. 3, No.2

The major difference between the existing and the proposed engineering curricula is the replacement of a unified system with two consecutive parts. The first part of the curricula, ending with a Bachelors degree, is less comprehensive than the current curricula, but it is sufficient for the graduate to commence their professional career. However, under the new system, a graduate can strengthen their knowledge by opting for the postgraduate program. Under this plan, both types of German universities would offer these courses. Consequently, the Fachhochschulen (Universities of Applied 
Science) will provide a more extensive academic program offered currently and the technical universities will be able to release a proportion of their students into professional practice sooner. The introduction of the new curricula would cloud the current distinction between the objectives of the two forms of tertiary institution. Figure 2 below indicates differences between the existing and proposed engineering curricula. ${ }^{4}$

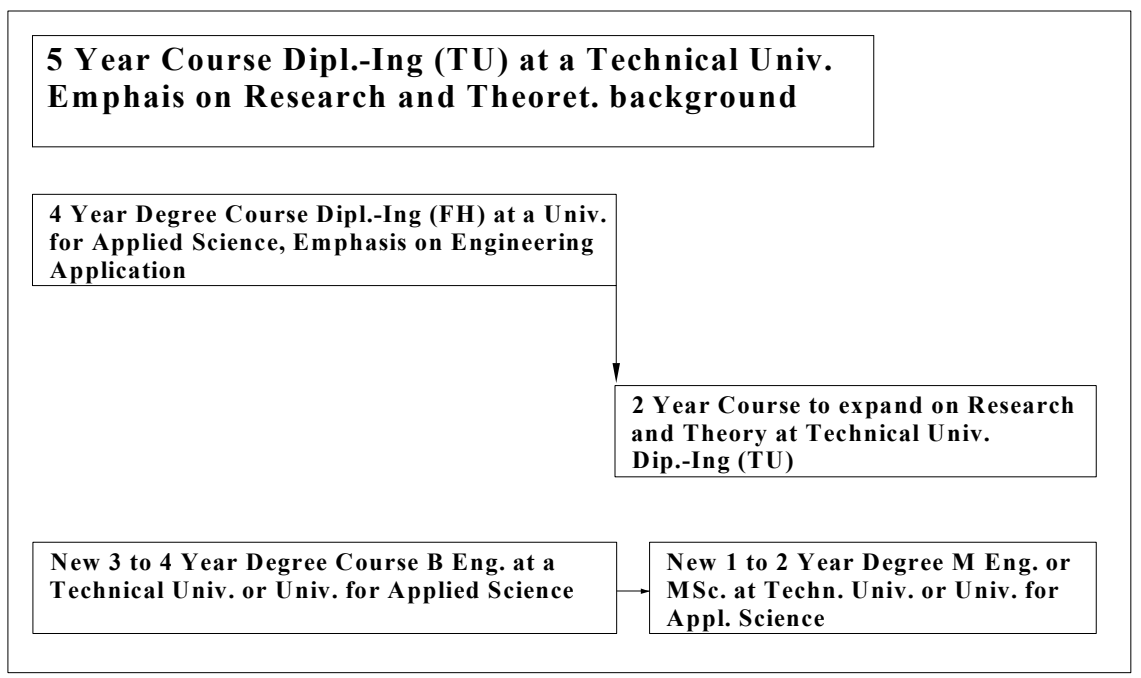

Figure 2: The system of engineering education in Germany. Adopted from Global J. of Engng. Educ., Vol. 3, No.2

Detert ${ }^{4}$ further explains the primary reason for this change as being that several highly respected universities in the USA, Great Britain and other English speaking countries have demonstrated the ability to adjust their engineering education effectively to address the demands of the global world. It can be argued that their flexibility is not due to the structure of their courses and curricula, but the considerable flexibility to develop their own profile, unlike German institutions. Strict compliance with governmental rules and regulations prevent German institutions to have the required autonomy to be flexible and change based on the needs of the society.

Questions are raised that whether the introduction of an Anglo-American system will be the solution that many Germans believe is needed (considering that the British Engineering Council is currently attempting to restructure the engineering degrees in British technical universities). The objective there is to offer two degrees in parallel (Figure 3). After three years of successful study, students will graduate with a Bachelors degree as an Incorporated Engineer. A new four year degree will allow students to graduate with a Master's degree, and, after four years of qualified industrial experience, they would receive the title of Chartered Engineer. The new system proposed for adoption in Britain closely resembles the current German system of engineering education, where technical universities and Fachhochschulen offer courses that are distinguished in their objectives and requirements. 


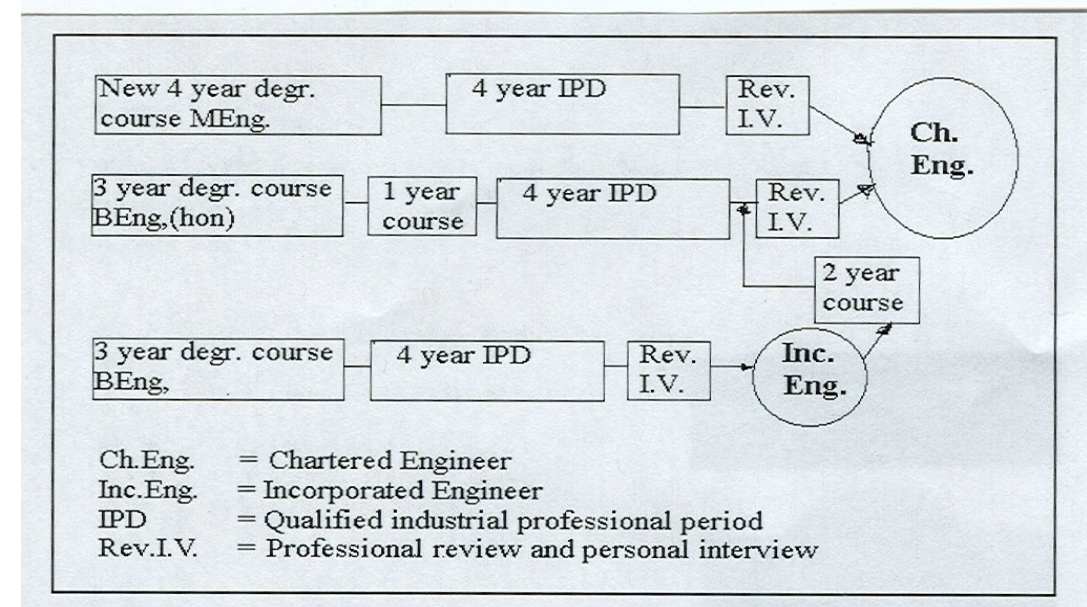

Figure 3: The system of academic engineering education in the United Kingdom (Sartor 97).

Figure adopted from Global J. of Engng. Educ., Vol. 3, No.2

\section{Global Engineering Education Status in the United State}

There have been multiple initiatives to make international engineering training more relevant and accessible to all engineering undergraduates in the United States. The Global Engineering College has the advantage of presenting a novel curricular model for engineering education called the Global Engineering College (GEC). The Global Engineering College GEC injects international perspectives into every aspect of the curriculum. The GEC concept utilizes recent technological advances to create a single "virtual" engineering college that integrates selected courses with parallel courses at the partnering institutions abroad. GEC allows students from one university to participate via internet in design courses offered at any partner university. This will provide access to the full array of specialized elective topics, laboratory equipment and practical experiences available at any participating university both in the country or abroad. ${ }^{5}$

The GEC model consists of four key elements that interact in complementary fashion, providing a wide range of international experience and training opportunities. These four key elements are: Curriculum Internationalization, Virtual Student Exchange (VSX), Global Internships, and Engineering-specific Language Instruction. The following is a brief description of each one of the elements:

Curriculum Internationalization - by replacing generic, context-free assignments and projects with "scenario-based" challenges in which the same pedagogic exercises are situated in international contexts, international perspectives included into existing engineering course curricula.

Virtual Student Exchange (VSX) - students in the U.S. and abroad will be able to participate in each other's design courses at a distance by utilizing internet technologies. This allows bringing the world into one classroom, ensuring that even students who can not go abroad are exposed to international collaboration. It will also enable students from one institution to gain access to a wide range of curricula offered at participating institutions.

"Proceedings of the 2005 American Society for Engineering Education Annual Conference \& Exposition Copyright (C) 2005, American Society for Engineering Education” 
Global Internships - "prerequisites for success in modern international corporate environments include sensitivity and adaptability to differences in work habits, differing legal environments, and respect for local customs and mores." For a motivated student, an essential part of the Global Engineering College model is to gain the experiential knowledge in an international workplace and streamlined access to a global internship experience. ${ }^{6}$

Engineering-Specific Language Instruction - Doerry, et. al. ${ }^{6}$ have developed a model for accelerated, engineering-specific language instruction providing engineering students with linguistic competence sufficient to attend engineering courses and/or to serve an engineering internship in the target language within a single year of study. The international engineering exposure is "built-in" the course curriculum, providing a core level of international exposure for all engineering undergraduates. The Global Engineering College model provides streamlined access to foreign culture and international engineering practice and increases global awareness for all students.

\section{Globalization Initiatives at Northern Kentucky University and other Regional Universities}

Unlike those graduates who start working in a developed country, graduates from developing countries will not have access to the advance technologies available at the fingertips of their first world counterparts. These engineers need to have the know-how to step-back and use more primitive tools to accomplish their tasks. This brings up the issue of technology dependency and the fact that not every engineer is blessed to have the latest technologies at their disposal. In this case, a global engineering education system will account for these conditions and provide the means to graduate engineers who can solve problems using the level of technology at hand. Therefore, nullifying the complete dependence on computers and other technologies to accomplish their tasks.

Introduction to Engineering, Technology, and Society IET 210 - is a new course offered at NKU, pending curriculum approval, introducing students to a range of issues involved in the study of science, technology, and society. Topics covered in this course will be: study of the relationships between science and technology, study of the social changes that result from the implications of certain technologies in different societies, international product life cycle and diffusion of technology, and factors involved in the rate of diffusion of engineering technology. ${ }^{7}$

Furthermore, the creation of a Virtual Center for Product Innovation and Commercialization (CPIC) is another globalization initiative. This initiative is a proposed consortium between three Kentucky universities including Northern Kentucky University, University of Louisville, University of Kentucky, and Purdue University dedicated to offering local and national businesses. This is an online resource center providing support, knowledge, and advice in the areas of product design and commercialization. Each university will offer resources related to their field of expertise 
through virtual media to students and clients. In addition to reaching a wider audience, this on-line service would reduce overhead costs for the universities. The site will offer a Blackboard-type interface, where clients can ask questions and have them answered by professionals. Called "Ask the Expert," this service will provide the clients with the opportunity to have their proposals reviewed and critiqued by professionals in the Consortium. Initially, CIPC would offer a number of modules to assist new businesses. Additional modules and features will be added at a later stage.

\section{Conclusion}

Today, boundary-lines between sovereign nations are fading away due to immense international trades and global community commerce. When one realizes the drastic effects of globalization, the urgency of a seamless international engineering education becomes apparent.

Globalization of Engineering Education mandates that graduates understand the cultures, traditions, and languages of countries where they will work. These engineers must understand the implications of their designs or end-products on the environment that the technology will be utilized. Engineering education in a given country or region must reflect and respond to local conditions.

\section{Bibliography}

1. Doerry, E. et. al. (2003). The Global Engineering College: exploring a new model for engineering education in a glabal economy, ASEE Proceedings, for the ASEE Annual Conference.

2. Gunnink, B. Sanford Bernhardt, K. L. (2002). WRITING, CRITICAL THINKING, AND ENGINEERING CURRICULA, 32nd ASEE/IEEE Frontiers in Education Conference, November 6 9, 2002, Boston, MA

3. Jones, R. C. (1998). Outcomes of the 1998 Global Congress on Engineering Education at Cracow, Poland, Global Status of Engineering Education, http://www.worldexpertise.com/global_status of engineering_edu.htm

4. Lehto, S. (2004). TRANSFORMING ENGINEERING EDUCATION FOR THE $21^{\text {ST }}$ CENTURRY AS AN ENGINEERING R\&D WORK BY USING THE SYSTEMS APPROACH, ASEE Proceedings, for the ASEE Annual Conference.

5. Detert, K. (1999). New Engineering Curricula in Germany: an Attempt to Modernize and Globalize Engineering Education, Global Journal of Engineering Education, Vol. 3, No. 2, Australia.

6. Doerry, E. et. al. (2004). The Global Engineering College: Lessons Learned in Exploring a New Model for International Engineering Education, ASEE Proceedings, for the ASEE Annual Conference.

7. Frame, J. D. (1983). International Business and Global Technology, Lexington Books, Lexington, Ms.

\section{MORTEZA SADAT-HOSSIENY}

Morteza Sadat-Hossieny is an Associate professor and a graduate faculty of Mechanical and Manufacturing Engineering Technology at Northern Kentucky University. Dr. Sadat-Hossieny is actively involved in consulting and research in different areas of Mechanical and Manufacturing Engineering Technology fields such as CADD, Automation, and technology transfer mechanisms. He regularly publishes papers in different proceedings and journals. 
Seyed Allameh is a full graduate faculty of Northern Kentucky University. Prior to joining NKU, Dr. Allameh conducted research at Princeton University for 5 years in the areas of MEMS, nanotechnology and advanced materials. He has served as a guest editor/editorial board of journals including Journals of Materials Science. Dr. Allameh holds a PhD from The Ohio State University. He has published over 60 scientific papers/book chapters.

\section{Mark RAJAI}

Dr. Rajai is an Associate professor of MST Program at Northern Kentucky University. He also serves as editor-in-chief of an international journal and is member of editorial board of several national and international journals. He has published several books and more than thirty articles and is recipient of several major grants and contracts. He is a nationally recognized researcher and major TV networksincluding $\mathrm{CNN}, \mathrm{ABC}$, and $\mathrm{BBC}$ - and numerous newspapers and radio stations have interviewed him. 